\title{
Theoretical Approaches to Definition of Regional Economic Stability
}

\author{
Khairullov D.S. \\ Belyaeva M.N.
}

Kazan Federal University, Institute of Management, Economics and Finance, Kazan, 420008, Russia

Email: belyaevamn@rambler.ru

\section{Doi:10.5901/mjss.2014.v5n28p86}

\begin{abstract}
The article describes the main theoretical approaches to the definition of the regional economic stability. Based on the analysis of existing theoretical approaches to regional economic stability the authors offer their own definition of economic stability of the region and also pay attention to technique of its estimation and conditions providing its maintenance
\end{abstract}

Keywords: region, economic stability, concept of economic stability of the region, conditions of regional economic stability, estimation technique of the region economic stability

\section{Introduction}

The modern requirements of the sustainable development for socio-economic systems lead to the need in development of the theory and methodology of economic stability, undertaking corresponding calculations, defining criteria and thresholds of socio- economic indicators determining the boundaries of effective and sustainable development of regions. Nevertheless we still do not have unified approach to interpretation of the term in economics.

\section{Theoretical Discussion: What is the Regional Economic Stability?}

The definition of sustainability has been borrowed by economic science from systems theory, when economic objects being considered as complex and diverse economic systems. In the usual sense stability means that the object is not exposed to fluctuations, it's stable and changeless. Stability of an object is shown in the fact that even under external influence it's able to return to its former state.

In the system analysis and synthesis stability is seen in complex of integral characteristics of an object reflecting its interaction with the environment, internal structure and behavior, so stability is one of the primary qualities of any system (Ostreikovsky, 2005). It's a relative category so we can estimate it only in comparison with other objects. The more stable is a state of the object which is less susceptible to changes, deviations from the previous state under the equal external influences. At the same time the condition of possessing resistance to external influences are intrinsic properties of the object itself. Consequently stability is the outer form, the external manifestation of the internal structure of the object. Basis of external sustainability lies within the object itself. In order to improve its stability we should improve the object inside.

Sustainability issues in relation to the economic problems were first reflected in the theoretical studies exploring the market equilibrium under condition of perfect competition (L. Walras, P. Samuelson, A.Wald) where were examined issues of market stability from the technical side namely in relation to economic processes and not to economic systems. Based on these models were obtained conclusion that underlie the formation of the modern theory of economic stability, in particular, findings about disparities in income distribution, inconsistencies between predictive expectations and actual results of economic life as the reasons for the loss of stability, strengthening the regulatory role of the state in order to maintain stability.

Issues of economic stability have got further development in the works of A.A.Bogdanov who has elaborated relation between the stability of systems of different levels, proved that stability of the system is determined largely by resistant structural links rather than elements.

This term suggests creative process, which should result in any good satisfying the specific needs of individuals or entities. Creative process is development of business units, and together with them and society as a whole. The 
development process is a form of movement through the time and space. Economic stability characterizes development of business entities and shows their ability not to deviate from the path of its development, to keep the pace, speed and volume of the creation of any goods under the influence of external factors.

Modern trends in the theory of economic stability are laid by neoinstitutionalism which believes the role of institutions is to reduce uncertainty by establishing a stable structure of interactions between economic agents. According V.A.Mau (Mau, 2008), it's institutional environment that provides the foundation of sustainable economic growth, which implies the conclusion of the institutional roots of economic stability in relation to the economic system at any level. Regional application of the concept were explored by A.G. Greenberg, S. Kuznetsov, etc.

At the end of the last millennium the problem of sustainability of economic systems received regular expansion in the global civilized concept of sustainable development scientific basis of which were elaborated by such scientists as Arnold V., Abalkin L., Aganbegyan A., AN Azrailyan , RS Greenberg and others. Besides investigating the issues of economic stability at the macro level they were developed also at micro level - enterprises, organizations and large corporations- in papers of Balabanov V., Karpovich A. and others. Thus, the problem of sustainability in economic science developed in two directions: at the micro - and meso-level for the national and regional economy as a whole as the concept of sustainable development, in which special attention is paid to environmental issues long-term plan; at the micro level, in relation of certain business entities (enterprises, firms, corporations) - as the concept of economic stability according to which main attention is paid to specific aspects of individual economic entities (financial, strategic, organizational and structural stability, reliability and economic security).

In the process of their development economic entities have to overcome not only the impact of factors that are external to them, such as, for example, inflation, growth of prices for raw materials, introduction of the new tax payments and many others, but also countering internal processes inherent to their own internal structure. Indeed, the development of any economic system is the interaction of opposing parties and trends arising from the intrinsic characteristics of these opposites. Outwardly it appears as self-development. Thus, for example, there is a tendency to reduce the exposure time for each separate unit of goods for workers affecting raw material during manufacturing process. However, in order to provide quality product, in line with certain technological standards and aesthetic forms - you need to spend time. Thus, under constant conditions of work the more time is spent the better item will be produced.

We can cause quite a lot of examples of such contradictions arising and developing within the economic entity. Dialectical unity of the many contradictions, the totality of their occurrence, development and resolution ultimately is the process of economic activity. Eliminating some controversy leads to appearance of another one with different content, at another level, etc. This process is infinite while economic activity is carried out.

The development process of an economic unit is its self-movement, self-development, folding of constant occurrence and overcome internal contradictions due to the structure and content of a business entity. However, this process of development as self-motion occurs in time and economic space. The less time is required to overcome and neutralize arising contradictions, the faster business entity develops.

In this effort of subjects of economic relations to the reduction of time to overcome the existing contradictions and lies an objective trend, special production need - regularity of sustainable development of economic entities. Economic stability of business entity is a vital factor of sustainable development. The higher economic sustainability is, the greater the ability of enterprises forming a regional economic system to resist market fluctuations and hence the lower the probability of their bankruptcy can be seen.

Vital condition of sustainable development is the state of inner balance, when all contradictions, speaking as opposites, neutralize actions and influence from each other and when they are mutually balanced. Economic entity is in a state of equilibrium when its each segment (or structural unit) is in private-equilibrium. Each private equilibrium is achieved at a certain structural level of the entity and at a certain stage of its development. Private equilibrium is possible only provided the aggregate of individual equilibriums of the contradictions inherent in this segment (or structural unit) at a certain stage (time interval). Individual equilibrium implies an equilibrium of separate contradiction based on the balance of opposites determining it. Thus, the total balance of the business entity is a complex multi-level system of the separate, individual and private equilibria. Taking this into account we agree with Safin F. that possibility of defining stable and unstable equilibrium depends on extent of balance equilibrium (Safin, 2007).

Stable equilibrium is the sequence of equilibria of different levels that provides economic entity with possibility to be restored after minor external impacts. Unstable equilibrium means that economic entity can not only be broken by external factors but also can lose opportunity to be recovered. Therefore, it is fair to say that the balance is the outward form of stability which is a complex of equilibrium at different levels - separate, individual and private equilibria. Stability of economic entity is higher when a set of its stable equilibria exceeds the number of unstable.

However, each time point is full of destruction of equilibrium is reached and the establishment of new ones. 
Destruction of equilibrium means the process of development that lays the possibility and conditions for the establishment of a new equilibrium at a higher level. Thus we can see reproduction of equilibria.

It is not necessary that a stable equilibrium is reproducted as a sustainable, it likely initially appears as unstable, fragile one. Whether it will become subsequently sustained or broken depends on how the development process of economic entity or its separate segment (structural units) will meet the requirements of the need to preserve and strengthen this even unstable equilibrium . Arisen unstable equilibrium can become stable one when the need for its development coincides with the general trend of development of an economic entity. Otherwise it will remain unstable and like any unstable phenomenon for a long time will not be able to survive and will be rapidly destroyed.

Economic stability of the region as a whole is determined by the economic sustainability of regional main industries. As economic stability of the production we understand its ability to resist and prevent exposure that could lead to a decline in production. Steadily developing may be called production that provides the necessary issue of consumer goods at the lowest cost with efficient use of factors of production and time.

The concept of economic stability of the region, thus, is linked to resistance of the material reproduction of regional economic complex and according to this it's seen as socially - economic concept and is defined as a system of economic relations providing continuous maintenance of stability or economic growth of the regional economy (Khairullov D.S., Eremeev L. M, 2012).

At the same time economic stability can be considered from two points of view:

From the viewpoint of maintaining the stability of any certain level of the final economic indicators. In this case we are talking about stabilization stability;

Economic stability as maintaining the stability of the incremental, marginal rates of economic growth, such as maintaining the annual growth of the gross regional product (GRP) or inflation within the set limits. In this case we mean the dynamic stability.

However, the stability of regional economic development also requires a set of conditions, factors and measures of regulatory impact, ensuring the stability of the final economic indicators. In this regard more attention should be paid to interrelation of stable regional development and economic stability of regional systems in framework of the mechanism of regional economic development, the source of which is the production of the gross regional product. That is, economic stability of regional system is the basis for sustainable development of the region.

\section{Research of the Regional Economic Stability Estimation}

Having studied contemporary works in estimation of economic stability we can distinguish the main approaches and provisions used in the development of methodologies for assessment:

1. Assessment of integral economic stability which includes all characteristics of the regional socio-economic stability: economic, production, financial, investment and social sustainability.

2. Summary estimates reflecting certain aspects of economic sustainability, including in dynamics.

3. Financial stability is seen a vital component of the economic stability that allows the use of standard ratios as the initial indicators of economic stability.

4. Bringing to the integral form of initial assessments is carried out by ranking, using the index method (Broilo, 2008).

Problems of regional economic stability are closely linked to sustainable development of the country economy. Elaboration of a program for sustainable economic development of the region should be based on the concept of transition of the Russian Federation and its regions to sustainable development. And it requires a strengthening of the role of state regulation of sustainable socio-economic development of the region.

State economic policy is aimed to achieve internal and external stability of the country. The internal economic stability implies such state of regional economy which is characterized by stable reproduction of territorial-economic complex, maintenance a level of employment. External economic stability can include balance of payments stability, maintaining a positive foreign trade balance, sufficient level of stabilization Fund. The main tools of state regulation in this case are such elements as its fiscal, financial, tax, pricing, tariffs, which affect the economic system in the region ensuring its stability.

\section{Conclusions}

Thus, in our sense economic stability of the region is the state of its economy defined by its economic potential (industrial, financial, employment, innovation, research, and natural) that can resist different negative impact leading to decline in 
regional economic development and recover quickly in case of violation or achievement a higher point in its development.

At the same time economic stability of the region is such state of the regional economy that maintains a constant process of expanded reproduction territorial-economic complex providing stable growth of the final performance and economic indicators. Estimation of economic stability of the region is the starting point of formation of science-based sustainable development of the region, which is particularly relevant in the current conditions of Russia's accession to the WTO.

\section{References}

Artyuhov V.V., Zabelin S.I., Lebedeva E.V., Martynov A.S., Mirutenko M.V., Ryzhov I.N. Ratings of sustainable development of the regions of Russia. - M.: "Interfax", 2011.

Broilo E.V. Methodology of crisis management sustainable development of business structures in the Northwestern region. - Syktyvkar, 2008

Bogdanov. A. Textology. Universal organizational science. - M.: Finance, 2003 - 496p.

Hamidullin F.G., Khairullov D.S., Khomenko V.V., Tarasov V.M. Problems of management of socio-economic development of the region. Kazan: FAN 2004-192p.

Khairullov D.S. Formation of state regulation system of the processes of socio-economic transformation and development of the Republic of Tatarstan, Kazan, "FAN". Tatarstan Academy of Sciences ,1997-236p.

Khairullov D.S. Management of social and economic security of the region. / / Economic Herald Republic of Tatarstan. - № 1Kazan.Tatarstanstat, 2012 - p.44-48.

Khairullov D.S., Eremeev L.M. Problems of regional socio-economic development stability. / / Bulletin of the Kazan Agricultural University. - Kazan: Kazan State Agrarian University, 2012. - p.73-77.

Mau V. Economic Policy in 2008: Successes and risks. / / Problems of Economics.- 2008 - №2- p.25.

Ostreykovsky V.A. Analysis of stability and controllability of dynamical systems using methods of catastrophe theory: Textbook for high schools. - M.: High school, 2005 - 326 p.

Safin F.M. Economic stability of the enterprise: the methods of evaluation and control mechanism. - Kazan, "FAN", 2007 - p.11-15.

Razumovskaya, E.M. , Kutsevol, N., Popov, M., Mishakin, T., Leto, L., Tsalikova, V. The effectiveness of management practice in the market of socially important services. Asian Social Science, Volume 10, 28 September 2014, Pages 118-122

Razumovskaya, E.M.,Lapidus, L.V., Mishakin, T.S., Popov, M.L. Features and peculiarities of the Russian passenger rail market development. Mediterranean Journal of Social Sciences vol. 5 (18 SPEC. ISSUE), pp. 165-170.

Safiullin Lenar, Fatkhiev Artur, Saipullaev Ullubi, Bagautdinova Nailya. Problems and decision in the field of distance education. Procedia - Social and Behavioral Sciences. Vol. 131, pp. 111-117 // 3rd World conference on educational technology researches Turkey 07-09.11.2013. 